National Research Council Canada

INSTITUTE FOR INFORMATION TECHNOLOGY

\title{
A PRACTICAL GUIDE TO ETHICAL RESEARCH INVOLVING HUMANS
}

Norman G. Vinson, JANiCE Singer.

Published as Vinson, N.G. \& Singer, J.A. (2008). A Practical Guide to Ethical Research Involving Humans, In Guide to Advanced Empirical Software Engineering (Shull, Singer, Sjøberg Eds.) pp. 229-256, Springer. 



\title{
A Practical GUide to Ethical Research InVOLVIng Humans ${ }^{1}$
}

\author{
NORMAN G. VINSON AND JANICE SINGER
}

\section{ABSTRACT}

The popularity of empirical methods in software engineering research is on the rise. Surveys, experiments, metrics, case studies, and field studies are examples of empirical methods used to investigate both software engineering processes and products. The increased application of such methods has also brought about an increase in discussions about adapting these methods to the particularities of software engineering. In contrast, the ethical issues raised by empirical methods have received little attention in the software engineering literature. In this chapter, we introduce four ethics principles of primary importance for conducting ethical research. We additionally discuss and provide examples of applying these principles in the context of ethics review.

\section{INTRODUCTION}

- How should an empirical researcher approach subjects?

- How should data be collected and stored?

- How can a researcher reduce subjects' unease about being observed? ${ }^{2}$

- Should a company's name be mentioned in the acknowledgements of a paper?

Each of these real-life issues has an ethical dimension. As such, ethics play a role in the proper management of a research project (Mirvis and Seashore, 1982) which, in turn, affects the project's success. Accordingly, it is important that empirical researchers understand research ethics and their application. In this chapter, we will introduce the major ethical concepts relating to Empirical Software Engineering (ESE) research with human subjects and provide a practical guide to the ethics review process ${ }^{3}$.

Because empirical research is relatively new to software engineering, discussion of the ethical issues raised by ESE is still in its early stages (Harrison, 1998; Jeffrey and Votta, 1999; Singer and Vinson, 2001, 2002). Therefore, we

${ }^{1}$ Based on Singer, J.A. \& Vinson, N.G. (2002). Ethical issues in empirical studies of software engineering, IEEE Transactions on Software Engineering 28(12), 1171-1180

${ }^{2}$ Several recent publications (e.g. National Health and Medical Research Council et al., 2007) suggest that it is more appropriate to refer to the people under study as research participants rather than research subjects. However others (e.g. Canadian Institutes of Health Research et al., 2005 ) note that the term "participant" is ambiguous, as it can refer to virtually anyone involved in the research project. To avoid any such ambiguity we will use the term "subject" to refer to those people who are being studied.

${ }^{3}$ Scientific research raises a host of ethical issues such as the assignment of authorship, the relationship between graduate students and their advisors, and scientific fraud. These issues apply broadly to most research disciplines (Committee on Science, 1992, 1993, 1995). Computer science and software engineering research raises additional issues (Wright, 2006). In this chapter, we will ignore broad issues to instead focus on the ethical issues raised by the researcher/subject relationship in ESE; issues such as those highlighted above. 
will rely on information from other fields to support our discussion. Nonetheless, our examples will focus on situations ESE researchers are likely to face.

It is insufficient to simply expect scientists to behave ethically (Beecher, 1966a; McNeill, 1993). In an attempt to minimize unethical behaviour, governments and scientific communities have developed codes of research ethics (McNeill, 1993). By providing a standard of behaviour for researchers to follow, and by helping them reason about ethical issues in specific situations, it is hoped that these codes of ethics will reduce the incidence of unethical behaviour (Anderson et al., 1993; Frankel, 1989; Gotterbarn et al., 1999; McNeill, 1993). However, it is ultimately up to individual researchers to ensure research practices are ethical. In this regard, experience has shown that to behave ethically, people must understand the ethical principles underlying codes of ethics and spend the time and effort required to intelligently apply them to their own circumstances (Anderson et al., 1993; Canadian Institutes of Health Research et al., 2005). To quote the preamble of the ACM/IEEE-CS SE Code of Ethics and Professional Practice, "the Code is not a simple ethical algorithm that generates ethical decisions" (Gotterbarn et al., 1999, p. 104).

Unfortunately, the ESE community has yet to develop its own code of research ethics (Harrison, 1998; Jeffrey and Votta, 1999; Singer and Vinson, 2002) Researchers must therefore try to apply codes from related disciplines to ESE studies. For ESE research practices similar to those of other disciplines, this does not pose a problem. In this vein, codes from the social sciences and computing sciences are especially relevant. However, for research practices more common or even unique to ESE, such as the use of source code as data (see El-Emam, 2001; Vinson and Singer, 2001), the existing codes are of little value. In these cases, ESE researchers will have to reason from ethical principles to determine an ethical course of action. To support such reasoning, we provide a detailed explanation of the main principles of ethical research in the first section of this chapter. We also describe some common problems in applying these principles to ESE projects and present solutions to those problems.

This chapter also includes a discussion of the role of Ethics Review Boards (ERBs) and research ethics regulations. In the USA, Canada, and Australia most ESE projects receiving government funding and involving human subjects must be reviewed by an ERB to ensure that the project complies with the relevant ethical guidelines (Australian Research Council (ARC), 2007; Canadian Institutes of Health Research et al., 2005; National Health and Medical Research Council et al., 2007; Penslar, 1993). However, because the regulations and guidelines still retain characteristics of their original focus on biomedical research (Canadian Association of University Teachers (CAUT), 1997; Lane, 2006; Sieber, 2001b), it can sometimes be difficult to determine whether and how they apply to ESE (El-Emam, 2001; Lethbridge, 2001; Sieber, 2001a, 2001b; Vinson and Singer, 2001; Vinson and Singer, 2004).

In general, Europe's regulations focus on biomedical research. However, the Research Council of Norway expects institutions to ensure that the necessary ethical precautions are taken (H.H. Simonsen, Senior Adviser, National Research Council of Norway, personal communication (e-mail), July 20, 2006). Similarly in the UK, the Engineering and Physical Sciences Research Council (EPSRC) holds the institution responsible for ensuring that research ethics standards are followed (Engineering and Physical Sciences Research Council (EPSRC), 2007, p. 31), but it does not appear that ESE research need be reviewed by an ERB or comply with a specific set of research ethics guidelines.

Europe does however have personal information privacy laws, as do Canada and Australia (Patrick, 2006). These laws conform in large part to the Organisation for Economic Co-operation and Development (OECD) Guidelines on the Protection of Privacy and Transborder Flows of Personal Data (Organisation for Economic Development and Co-operation (OECD), 1980; Patrick, 2006). While specific implementations will differ from country to country, they 
will rest on the principles we describe below. Moreover, researchers should note that it is not within the mandate of ERBs to ensure compliance to privacy laws.

In reading this chapter it is important to keep in mind the important distinction between principles and regulations: research practices are rendered ethical primarily by the application of ethics principles. Principles, if they are abstract enough, can be applied to any relevant situation. In contrast, existing regulations are not well suited to all research situations that raise ethical issues (Sieber, 2001a, b; Singer and Vinson, 2002). Consequently, simply complying with regulations can nonetheless result in violations of the principles of ethical research (Beecher, 1966a; McNeill, 1993). The distinction between rules and principles is particularly important for ESE researchers since some of their research practices are not covered by existing regulations (Sieber, 2001a; Singer and Vinson, 2002). In order to conduct research ethically, ESE researchers must not simply rely on complying with the rules but must be able to apply ethical principles to their particular circumstances (Gotterbarn et al., 1999).

Accordingly, our goals in this chapter are to introduce the topic of research ethics, aid researchers with the ethics review process, and foster ethical decision-making in the context of ESE research. In service of these goals we will first focus on ethical principles and then present sample ERB documents. Knowledge of both these components is vital to planning and conducting research projects.

\section{ETHICAL PRINCIPLES}

Singer and Vinson (2002) reviewed codes of ethics from government funding bodies, and biomedical, social science, and computing science professional organizations to determine common principles relevant to ESE research practices. They discovered four such common principles: informed consent, scientific value, confidentiality, and beneficence. The principle of informed consent stipulates that potential subjects should be informed of all relevant facts about a study before making an explicit, free and well-considered decision about whether to participate. The study should also have some scientific value in order to call upon human subjects to expose themselves to even minimal risks. Researchers must also undertake every effort to maintain the confidentiality of data and sensitive information. Finally, beneficence results from a weighing of the risks, harms, and benefits of the proposed research. Beneficence must be positive in order to proceed.

Note that all of these principles apply whether researchers are observing the subjects' behaviour directly (as in job shadowing (see Singer et al., Chap. 1)), or indirectly (as when collecting command logs), or whether the subjects are simply providing code to be examined. These principles also apply whether the subjects are students, employees, volunteers, or organizations (e.g. companies). Each of these principles is reviewed below, and the implications for ESE researchers are discussed.

\subsection{INFORMED CONSENT}

The principle of full informed consent on the part of research subjects to participate in a study follows from the more abstract principle of respecting an individual's autonomy (Fleuhr-Lobban, 1994). In essence, before the research begins, potential subjects have the right to choose whether they will participate in the project. Ethicists do not agree on the necessary components of full informed consent, but it is clear that it must contain at least some of the following elements: disclosure, comprehension and competence, voluntariness, and the actual consent or decision (Faden and Beauchamp, 1986). Below we provide an abstract description of each of these elements and then we focus more closely on consent in the context of ESE. 
Disclosure refers to the information that the researcher must provide to the subjects for them to make an informed decision about whether to participate in the research. This information usually includes, but is not limited to: the purpose of the research, the research procedure, the risks to the subjects, the anticipated benefits to the subjects and the world at large, alternatives to participation (typically for students in a subject pool), the treatment of confidential information, the voluntary nature of participation, and a statement offering to answer the subjects' questions (Sieber, 1992). As well, the disclosure should describe the type of data that will be collected and the uses it will be put to (Patrick, 2006). The intent is to provide potential subjects with all the information necessary to understand how the research will affect them (Faden and Beauchamp, 1986). The need for comprehension compels the researcher to present the information in a manner that the subjects can understand, e.g. eschewing technical jargon that is outside the subjects' repertoire. Competence refers to the subjects' ability to make a rational informed decision to participate in the research. This element is intended to protect vulnerable subjects who may not understand the nature of the research or the risks, such as children or the mentally disabled. Finally, voluntariness specifies that informed consent must be obtained under conditions free of coercion and undue influence, and that the consent must be intentional. The subjects' right to terminate their participation at any time is also a component of voluntariness. Typically, the decision to participate must represent an active authorization on the part of the subject, as opposed to a tacit acceptance or mere formality (Faden and Beauchamp, 1986). In regard to the specific elements of informed consent - disclosure, comprehension and competence, voluntariness, and the actual consent or decision - ESE researchers are not likely to have trouble with comprehension and competence.

For field research in companies, it will almost always be necessary to obtain consent from the company first, whether one is interviewing employees or simply obtaining metrics on source code (ACM Executive Council, 1993). The wise researcher will also try to convince the relevant managers to support the project.

When an individual can be identified from the data, consent is usually required, regardless of the way in which the data are collected (Patrick, 2006). Indeed, the ACM code (ACM Executive Council, 1993) explicitly forbids access to an individual's electronic data and communications, such as e-mail, without the individual's prior consent. In contrast, when there is no information in the raw data that could allow a particular individual to be identified, informed consent of individuals will usually not be required (Canadian Institutes of Health Research et al., 2005; Penslar, 1993). For example, measurements of network traffic do not include data identifying individuals, therefore, the informed consent of employees using the network would not be required even though the employees are the source of some of the data.

Obtaining signed informed consent forms in participant observation field research will often pose a problem (Fleuhr-Lobban, 1994; University of Toronto Social Sciences and Humanities Research Ethics Board (SSH REB), 2005). When using participant observation methods, the researcher becomes a member of the community that is the object of study (Singer et al., Chap. 1; University of Toronto Social Sciences and Humanities Research Ethics Board (SSH REB), 2005). In these contexts, consent is an ongoing process. For example, as the research evolves, the participants' (subjects and researchers) roles will change and unforeseen risks may arise (Fleuhr-Lobban, 1994; Mirvis and Seashore, 1982; University of Toronto Social Sciences and Humanities Research Ethics Board (SSH REB), 2005). Given the changing participant roles and the evolution of the research, it is practically impossible to even 
prepare a consent form as described in the ethics regulations (see 45CFR§46 ${ }^{4}$; Canadian Institutes of Health Research et al., 2005).

At the outset of the study, the subjects should receive as much disclosure about the study as possible, perhaps through a general announcement. Subjects should also be made aware that their behaviour might be recorded. In addition, given the evolving nature of the research, the researcher should maintain an ongoing dialog with the subjects, apprising them of relevant changes that can affect their consent (American Anthropological Association, 2004; Fleuhr-Lobban, 1994; University of Toronto Social Sciences and Humanities Research Ethics Board (SSH REB), 2005).

A distinction can be drawn between consent and assent, the latter being more passive, more similar to acquiescence. When giving consent, the subject is required to sign an informed consent document. In contrast, assent is limited to a verbal or tacit agreement to participate. For telephone interviews or surveys, assent (in contrast to consent) is usually acceptable (Fowler, 1993), as long as the study poses no real risk to the subjects and there is no collection of information that could be used to identify the subjects. To give assent, subjects still need all the necessary information to make an informed decision about whether to participate in the research. They simply do not have to sign a form (Fowler, 1993). In a participant observation context, the researcher's primary subjects may sign a consent form at the study's outset, and then maintain their participation through assent as the study evolves. For other participants whose interaction with the researcher is limited, assent may be sufficient (University of Toronto Social Sciences and Humanities Research Ethics Board (SSH REB), 2005).

Many codes of ethics (e.g., Canadian Institutes of Health Research et al., 2005) set full disclosure as the standard for an acceptable informed consent. Full disclosure is defined in contrast to deception, where the true intent and methods of the study are not revealed to the subjects. For example, a social science researcher might be interested in how women and men interact in small spaces. To examine this, the scientist sets up an experiment in which subjects are told that they will process some paperwork with a partner. They are led to believe that the partner, like them, is a subject. However, in reality, the partner is part of the experimenter's team and is only pretending to be a subject. The partner's role is to engage the subject in particular ways. The effects of those different engagement techniques on the subjects' behaviour are the true focus of the experiment. To avoid biasing the subjects' responses, the subjects are told nothing of this, and therein lay the deceit.

Rather than full disclosure or deception, many ESE studies employ some form of partial disclosure. Partial disclosure refers to providing the subjects with a less than complete account of the study's goal or hypotheses. If the subjects knew the hypotheses in detail, they could well modify their behaviour as a function of this knowledge, thus invalidating their data (Sieber, 1992; Worchel and Cooper, 1979). For example, consider an ESE experiment on source code searching. The experimenters could partially disclose the goal of the study by simply telling subjects that their patterns of file access and use will be recorded and examined. The experimenters mask the true goal of the study by formulating it in a more general, abstract, and vague manner. After the subjects have completed the experiment, they are provided with more detailed explanations of the experiment's goals and hypotheses. Since the subjects' data have already been collected, these explanations will not affect the data's validity. This is the least objectionable form of partial disclosure, since it does not affect the subjects' assessments of the risks of

${ }^{4}$ Listed in the references section as: Public Welfare, Protection of Human Subjects, Code of Federal Regulations, Title 45, Pt. 46 (45CFR§46), (2005), http://www.hhs.gov/ohrp/humansubjects/ guidance/45cfr46.htm 
participation; full disclosure is provided at the conclusion of the experiment (Smith and Richardson, 1983); and no outright deception is involved.

It is unlikely that research in software engineering will involve any great form of deception. Nonetheless, Sieber (1992) gives excellent guidance, and Smith and Richardson (1983) discuss the crucial role of debriefing in deception experiments.

Perhaps the most important aspect of disclosure is the risks of participation. Many of the risks to subjects in ESE studies result from breaches of confidentiality. When employees serve as subjects, research reports can provide enough information for managers (or other employees) to identify the data of individuals. This can adversely affect the subjects' careers if, for example, it is found that they did not follow company procedures. Companies can also suffer if sensitive information is disclosed (see Sect. 2.2 Beneficence for other examples). It is therefore important to inform the subjects of the limits of confidentiality and the risks resulting from breaches of confidentiality as part of the disclosure process. Note that it is also advisable to minimize these risks by employing the techniques presented below in the section on confidentiality.

An additional difficulty in ESE is that the limited autonomy of many potential subjects raises questions about voluntariness. Namely, employees of a company that has approved a workplace research project and students in the researcher's class may fear a reprisal for not participating or may anticipate a reward for participating. For instance, an employee may fear upsetting his manager who supports the project, and a student may wish to curry her professor's favour. These expectations, even if they are false, taint the consent-giving process (Penslar, 1993). Of course, employees are only vulnerable if their employer has approved (or disapproved) of the research project. Research taking place outside the workplace context does not raise the possibility of employer coercion, even if it calls upon knowledge of software engineering.

Several measures can be taken to reduce the perception of coercion. First, in the case of field studies, researchers should emphasize to the potential subjects, and their managers if applicable, the importance of voluntariness and confidentiality of both participation and data. Second, researchers should establish explicit procedures to protect confidentiality (see Sect. 2.3). If managers and professors do not know who is participating, they can neither punish non-participants nor reward subjects. Consequently, their influence over potential subjects is significantly diminished.

However, it is easy to conceive of cases in which the research project would be carried out regardless of whether individual SEs consented or not (Vinson and Singer, 2004). This is because, as employees of a company, SEs can be directed by their managers to perform certain activities. In short, SEs are not fully autonomous in the context of their employment. Unfortunately, respect of the individual's autonomy is the cornerstone of research ethics guidelines and regulations (Fleuhr-Lobban, 1994). Thus in some cases, ESE field studies can conflict fundamentally with research ethics guidelines and regulations in regard to the subject's autonomy (Vinson and Singer, 2004).

For example a company may want metrics for several modules of code. Since the code belongs to the company, it has a legal right to obtain code metrics, regardless of whether the SEs or development group managers consent to it. In such a case, should a metrics researcher be required to obtain the consent of the individual SEs and their managers before working on the project?

For studies involving students, researchers should avoid recruiting students in the classroom setting and should avoid trying to recruit their own students. For example, an upcoming study could be announced in every class, and interested students would place their names on a list held in a secretary's office. This reduces the possibility and 
the perception of intimidation. Researchers should also ensure that the study has no impact on the students' grades. This not only reduces the possibility of coercion, it also minimizes the risk of harming subjects through their grades (refer to Sect. 2.2). Finally, students should also be given the opportunity of withholding their data.

In sum, ESE researchers must obtain informed consent from their subjects, whether these are individuals or organizations. However, it is unclear whether consent must be obtained from programmers when the research project is limited to examining source code they do not own. Disclosure is a required component of the consent process since it allows potential subjects to assess the desirability of participation. However, if the risks are clearly stated, partial disclosure that simply masks the precise hypotheses being tested should be acceptable. Perhaps the most serious difficulty for ESE researchers is the requirement of voluntariness. Voluntariness is threatened by the potential for coercion (real or merely perceived) of the employees and students. To limit the effects of coercion, researchers can implement procedures to protect confidentiality and minimize the harm that would result from breaches of confidentially. Techniques to minimize harm and protect confidentiality are discussed in the following sections.

\subsection{BENEFICENCE}

The degree of beneficence results from a weighted combination of risks, harms, and benefits to the subjects and society from participation in a study (McNeill, 1993). Researchers are required to maximize beneficence, particularly for research subjects. In ESE, benefits tend to arise from the research topic (e.g. better training software), whereas potential harm tends to arise from the research methods (e.g. having some students use the training software instead of coming to class). Consequently, once the research question has been chosen, researchers can usually maximize beneficence by adopting methods that minimize the risk of harm to the subjects.

The principle of beneficence applies not only to the individual subject, but also to groups of subjects, like particular ethnic or socio-economic groups (Canadian Institutes of Health Research et al., 2005), and/or organizations, like companies. Moreover, in the context of minimizing harm, the definition of "harm" is not limited to physical harm. Instead, it is very broadly construed, and contains such diverse elements as stress, the loss of dignity, self-esteem, or personal autonomy, the disruption of day-to-day activities, tedium, and of course financial harm (National Health and Medical Research Council et al., 2007; Sieber, 2001b).

In ESE, the greatest risk for harm often comes from breaches of confidentiality. Imagine, for instance, that a metrics project allows a company to rank its programmers by injected fault rate. An employee's ranking could then affect future promotions. ESE research can also harm organizations through financial loss resulting from the disclosure of sensitive information. For example, a researcher may evaluate source code from several companies and name the companies in an appendix to a published article. Negative evaluations could lead prospective clients to choose competing products. Accordingly, procedures that maintain confidentiality reduce the risks of harm. Such procedures are discussed below in the section on confidentiality.

Social science research methods used in ESE studies also have a potential for harm. For example, job shadowing, wherein a researcher closely observes a subject at work, can cause some people a great deal of stress. The risk of such harm can be minimized by respecting and emphasizing the informed consent provisions discussed earlier. In particular, when a subject shows discomfort, the researcher can ask if anything can be done to alleviate the discomfort and may remind the subject that she can withdraw from the study without penalty. Interview and observation sessions should be scheduled in consultation with the subjects to avoid times of high stress, such as immediately before a software release. Schrier (1992) details several other techniques to reduce the stress that can arise from being observed. 
In the context of ESE, researchers may take on the role of software engineers. The activities performed in this applied context can also harm the subjects, raising ethical issues (Lethbridge, 2001). For example, consider a project on source code re-engineering and automated translation. This will have a substantial impact on the software engineers who maintain the code, especially if they do not know the new code's language. At the very least it will increase their stress, and at worse it will place their employment at risk. Procedures can be implemented to minimize the impact of the source changes on the software engineers. For example, researchers can arrange for the software engineers to receive training in the new code's language. Researchers who introduce or modify technology should also avoid any action that might damage the subject's property. To continue our example of code translation, it is the researchers' responsibility to ensure that the translated code functions correctly even though, in practice, testing and debugging will often be carried out jointly by the researchers and the industrial partners. Similar issues arise when introducing new software tools or modifying interfaces (Lethbridge, 2001). When researchers take on the role of information technology provider, as illustrated here, they can find guidance in the ACM and IEEE-CS/ACM SE codes of ethics. It is not clear how and even whether research ethics regulations apply in these kinds of contexts (Lethbridge, 2001; Sieber, 2001a). However, it is clear that the ethical issues that can arise often fall outside the scope of research ethics. Mirvis and Seashore (1982) extensively discuss such ethical issues from the perspective of the various roles a researcher may adopt in an applied field research project.

Beneficence can lead to an ethical quandary when studying an organization and/or its members, or a company and its employees. In these cases, the reduction of harm to individuals may be at odds with the reduction of harm to the organization. For instance, if researchers uncover problematic processes in a company, whose harm should they attempt to minimize? To minimize harm to the company, the researchers should inform management of problems that could harm the company through increased costs and reduced product quality. However this could result in dismissals, thus harming individuals (Becker-Kornstaedt, 2001).

In the case of student subjects, classroom studies have the potential of harming subjects' learning and grades. For example, a classroom study comparing different software development environments, each used by a different group of students for class assignments, may influence the students' grades. In contrast, a 1-h laboratory study involving bug fixing should have no impact on grades. Consequently, a laboratory study is more acceptable from an ethical perspective than a classroom study. If methodological considerations force the researcher to use the classroom setting, several measures can be taken to improve its ethical acceptability. To reduce the effect of the manipulated factor (e.g. type of programming environment) on grades, each group of students could in turn be exposed to each level of factor. Over the course of the semester, each student would have his grade affected by all levels of the factor, rather than just one. Another possibility is to normalize the grades across student groups.

To summarize, in many cases, risks of harm can be minimized by protecting confidentiality. However researchers should use the least harmful yet still methodologically valid procedure. Here, codes of ethics can provide some guidance, but approaching the problem analytically and creatively will likely prove more useful.

\subsection{CONFIDENTIALITY}

The principle of confidentiality refers to the subjects' right to expect that any information they share with researchers will remain confidential. In general, researchers should also conceal and protect subjects' identities, whether they are individuals or organizations such as departments in a company or companies themselves. Moreover, even information that is not directly related to the research project should be considered private and kept confidential. 
Confidentiality has three components: data privacy, data anonymity, and anonymity of participation. Data privacy refers to the limitations imposed on access to the data collected from the subjects. To maintain data privacy, the data should be securely stored, with password protection and/or under lock and key. Access should be limited to a small number of people, all of whom would normally be part of the research team (Patrick, 2006).

Data anonymity is preserved when an examination of the data cannot reveal the identity of the subjects. There are several means to preserve the anonymity of the data. First, if at all possible, researchers should not collect any personal or organizational information that could lead to the identification of the subjects (ACM Executive Council, 1993; Patrick, 2006). Such information is typically referred to as personally identifiable information, identifiable private information (45CFR $\left.\$ 46.102(f)^{4}\right)$ or identifiers. Avoiding the collection of personally identifiable information reduces the possibility of breaches of confidentiality, and may even allow researchers to avoid the requirement to obtain informed consent. For example, subject numbers can be used instead of subject names. (However, if the names were needed for a follow-up, a key linking the names to the numbers would be securely stored apart from the data, preserving some degree of data anonymity.) Note that personal characteristics other than names could also serve as identifiers. For example, someone who knows the subjects could use programming experience to associate some of the data to some of the subjects. Another way to anonymize data is to report only aggregated data (such as cross-subject averages, medians, standard deviations, etc.) instead of individual data points. Unfortunately, ESE studies are often conducted with only a small number of subjects so that it may be impossible to anonymize the data by simply aggregating data across subjects. In this case, it is important to disclose the limits of confidentiality to subjects before they decide to participate in the research.

Anonymity of participation is accomplished by hiding the identity of the subjects from their colleagues, managers, professors, competitors, clients, and the public. Protecting the subjects' identities from managers and professors is particularly important since they can have the greatest impact on the subjects' careers. Competitors and clients have the greatest impact on companies and organizations, so researchers should be particularly sensitive to concealing the names and identifying characteristics of companies participating in research.

Recruitment should take place through some means that protects the subjects' identities. For example, e-mail and sign up sheets that are only accessible to the researchers offer some identity protection. Additionally, sampling from a large pool of potential participants can protect the subjects' identities. Therefore if an employee or student is not participating in the research, the manager or professor does not know whether the employee or student declined to participate or simply was not asked to participate (assuming, of course, that neither the professor nor the manager is an experimenter).

For data collection, it is best to see subjects in a private area. However, this cannot always be accomplished, as with observational studies in open office (cubicle) settings. Anonymity could still be maintained through remote observation (e.g. command logs) or observation at a time when confidentiality will not be breached, such as early in the morning, or when a manager has a meeting. If neither of these solutions is feasible, the potential subjects must be informed of the limits of confidentiality before agreeing to participate.

Names of subjects or organizations should not be reported, even in the acknowledgements section. Protecting the subjects' identities in the body of a paper makes little sense if identifying information is provided in the acknowledgements. Where an identifier is necessary for clarity, authors should use misleading pseudonyms. One should also avoid reporting identifying characteristics of companies under study. This is not always possible, particularly with case studies. If identifying characteristics will have to be reported, the executives providing consent should be informed of the resulting limits of confidentiality. Moreover, executives sometimes request that 
their company by identified. In such a case, researchers should inform them of the potential risks, and proceed with what makes the most sense.

The importance of confidentiality should be emphasized to all of those involved in the study, whether they are researchers, research assistants, subjects, managers or professors. Breaches in confidentiality lead to breakdowns in trust between researchers and subject populations. This loss of trust can leave a researcher without access to a subject population. It is therefore paramount to protect the confidentiality of subjects and their data, and to inform subjects of any limits to confidentiality.

\subsection{SCientific Value}

Scientific value has two components: the validity of the study, and the importance of the research topic (McNeill, 1993; National Health and Medical Research Council et al., 2007). First, if the study is not methodologically valid, its results will not faithfully reflect reality. Consequently, the study will provide no benefit. A study without benefit should not be undertaken (Freedman, 1987; McNeill, 1993).

In many of the codes of ethics promulgated by professions, the issue of competence is the counterpart to the issue of scientific validity (e.g. American Psychological Association, 2002). In the context of ESE, competence refers to an understanding of the standard research and statistical methodologies. ESE researchers should therefore be familiar with the appropriate and relevant methodologies or consult with other professionals who possess the necessary competence.

Because ESE is a relatively new approach, if not a new field, there is still a great deal of activity in the development of new methodologies, particularly in regard to metrics. Methodological development poses a problem for evaluating scientific value. Since it is difficult to assess a new methodology's validity, precisely because it is new, it is difficult to assess the scientific value of the development of that methodology. One way to validate a new methodology is by using it to replicate well-established results. ESE researchers wishing to develop and use a new methodology should consider validating this methodology through replication as soon as possible.

The previous sections of this chapter reviewed four ethical principles paramount to conducting ethical research in ESE. Researchers should be familiar with these principles and know how to apply them to their research projects. It is not sufficient to simply follow a set of regulations. Each decision regarding ethics should be made in consideration of the underlying principles.

The next section of the chapter introduces project review by summarizing the history of the regulation of research by governments, and defining some common terms associated with ethics review.

\section{Project ReView}

Several governments have mandated that an independent ERB review proposed research involving human subjects to ensure compliance with ethical guidelines. Canada, Australia, and increasingly the UK, are following the lead established by the United States (45CFR§46 ${ }^{4}$; Canadian Institutes of Health Research et al., 2005; Economic and Social Research Council (ESRC), undated; McNeill, 1993; National Health and Medical Research Council et al., 2007). In this section, we describe project review and its associated documents primarily from the US perspective since it has the most established process. This section, especially the example documents, provides a very concrete (though limited) illustration of how to apply the ethics principles discussed above. Accordingly, the information presented here is useful for all researchers, including those in Europe who do not yet face project review. 
In the United States, regulations requiring ethics review were put into place following the Jewish Chronic Disease Hospital case (McNeill, 1993). This case involved hospital researchers who injected live cancer cells into patients without their consent. Because the study was partially funded by the US federal government, the scandal spurred the government to require ethics review of federally funded research. Subsequent ethical transgressions eventually led to the creation of the Common Rule (45CFR§46 ${ }^{4}$ ), the US federal regulation governing the ethics of research projects involving humans (McNeill, 1993). By 1991, the Common Rule had been adopted by several federal agencies, among them the National Science Foundation, the Department of Education, the Department of Defence, and NASA, which are the government agencies most likely to fund software engineering research. This means that all research funded by these agencies is bound by the Common Rule regulations (Sieber, 2001b).

The Common Rule requires that all research involving human subjects be reviewed by an Institutional Review Board (IRB) (Penslar, 1993) (which we refer to as an Ethics Review Board (ERB), as the specific terms for ERBs differ from country to country). The ERB is an administrative body whose mandate is to protect the rights of research subjects. Generally, each university or government agency has its own ERB to review all human subjects research projects conducted by members of the ERB's institution. Companies whose research is funded by the federal government may also have an ERB or contract the services of private ERBs (Heath, 1998; Penslar, 1993). In the US and Canada, the ERB has the authority to approve, reject, propose modifications to, or terminate any proposed or ongoing research involving human subjects under its jurisdiction (Penslar, 1993; 45CFRß46.113 ${ }^{4}$; Canadian Institutes of Health Research et al., 2005). In Australia, it is the institution that has the responsibility to ensure compliance with the national ethics statement (National Health and Medical Research Council et al., 2007).

Only projects constituting research that involves human subjects are subject to ERB review. It is the ERB's responsibility to determine whether the proposed project constitutes research and whether it involves human subjects. Research is defined in the Common Rule as "a systematic investigation, including research, development, testing and evaluation, designed to develop or contribute to generalizable knowledge" (45CFR§46.102(d) ${ }^{4}$ ). The key phrase here is "generalizable knowledge". Generalisable knowledge is not considered to result from quality assurance or performance reviews undertaken within a specific context. For example, the evaluation of a professor's performance through the use of student questionnaires would not be considered research because it does not contribute to generalisable knowledge in that the knowledge applies only to that professor. On the other hand, collecting student questionnaires to determine the characteristics of excellent professors constitutes research because generalisable knowledge is produced in that the resulting "excellent professor" profile can be compared to the profile of any other professor.

Some forms of human subjects research are typically exempt from ERB review. The two most important exemptions for ESE research are surveys and the development of educational tests and materials. For a project to be exempted from review, the data must not contain any information that can lead to the identification of individual subjects. Additionally, reporting the data must not place the subjects at risk for loss of employment, liability, financial loss or other risks to the subjects' good standing in the community (Penslar, 1993). In general, then, when conducting surveys or collecting evaluative education data, it is best to refrain from collecting any information that could lead to the identification of an individual's data (Patrick, 2006). Researchers should note that there is some confusion over what constitutes research and that some regulations are unclear on the matter (Canadian Institutes of Health Research et al., 2005; Lethbridge, 2001; Sieber, 2001a). Consequently, we recommend that researchers consult with their ERB when in doubt about whether their work constitutes research, and whether it is subject to review. 
Besides determining whether a proposal involves research, the ERB must also determine whether it involves human subjects. The Common Rule specifies that, to involve human subjects, the research must involve the collection of identifiable private information or data from living individuals by interacting with them or manipulating their environment. "Identifiable private information" refers to information that is normally not observed, recorded, or made public and can be used to identify the subject who is the source of this information (45CFR§46.102(f) $\left.)^{4}\right)$. For example, someone's opinion about the utility of design reviews is typically considered private information. In contrast, an opinion about design reviews that is published in an article is considered to be in the public domain, and consequently, does not constitute private information. US and Canadian regulations explicitly exclude the collection of public domain data from the definition of human subjects research (45CFR§46.101(b)(4) ${ }^{4}$; Canadian Institutes of Health Research et al., 2005).

This definition of human subjects research leads to an interesting problem for software engineering research. In particular, when source code is used as a data source and individual programmers' identities can be used as a variable in the analysis, it is not clear whether the research comes under the purview of the ERB (EI-Emam, 2001; Vinson and Singer, 2001). It could be argued that when the programmers identified themselves as authors of a certain piece of source code, they had a reasonable expectation that this information would not be made public. Of course, this would probably differ for open-source projects or information collected from internet sources. Nonetheless, it is not entirely clear whether such a project must be reviewed. Again, when in doubt, consult the local ERB.

In summary, projects that receive Canadian, Australian or US federal funding and involve research with human subjects are required, in most cases, to be reviewed by an ERB to ensure that it meets the relevant ethical standards. If investigators are unsure about whether their research must undergo review, they should consult their local ERB. Avoiding ethics review when regulations specify that it is necessary can result in loss of funding, not only for the researchers involved but also for their institution as a whole. Therefore, ethics review and approval protects not only research subjects, but the researchers as well. Finally, whether a project is subject to review or not, it is prudent to adhere to the standards of ethical research. These standards help researchers avoid the type of conflicts that can jeopardize access to the subject population and the validity of the results.

\subsection{Planning for Ethics Review}

Planning for ethics review should be integral to the human subjects research process. Though approval times vary across institutions, it can take a considerable amount of time for a project to be approved, particularly if it contains controversial elements. For example, one local field study Singer conducted with employees as subjects took over 4 months to be approved. Proper planning can reduce approval time by increasing the odds that the proposal will be approved at the first review meeting. Part of this planning should include talking to colleagues who have already had a proposal approved, as they can provide much information about appropriate forms and the ERB review process.

To aid researchers in this endeavour, in the following sections, we describe the review process and provide examples of documents generally required by ERBs to review research proposals. We also relate the forms' contents to the ethics principles discussed earlier.

\subsection{ReVIEW PROcess}

Most institutions have their own ERB with its own procedures. However, the process typically begins with the researcher submitting documents describing the proposed project to the ERB. (Note that potential subjects cannot 
even be approached before the ERB has approved the project.) The ERB chair will then determine whether the project involves more than minimal risk. Minimal risk research is generally defined as research involving the same degree of risk that people normally encounter in their daily lives (Penslar, 1993). Moreover, to be judged of minimal risk, research must not involve vulnerable subject populations, such as students or employees of a sponsoring or collaborating company. Employees and students are considered vulnerable due to the potential for coercion or undue influence from employers or professors (Penslar, 1993). Projects that involve more than minimal risk are generally reviewed by the full board at periodic board meetings. In contrast, minimal risk projects are often given expedited review, wherein only a few board members need review the project. Moreover, since expedited review does not require a board meeting, it is usually faster than full (board) review.

Some ERBs will also require a scientific review to ensure the project has sufficient scientific value. The requirement for scientific review can depend on the project's level of risk.

Departments in which minimal risk human subjects research is a frequent occurrence sometimes have the authority to review and approve projects directly rather than submitting them to the institutional ERB. However, this is unlikely to be the case in computer science or software engineering departments, where few, if any, departmental ERBs exist. Moreover, in Canada, regulations forbid such departmental review boards, except for undergraduate research projects in the context of a specific course (Article 1.4a, Canadian Institutes of Health Research et al., 2005).

Projects are not always approved at first consideration. Moreover, when an ERB requires changes or amendments to the original proposal, the changes or amendments must usually also be reviewed by the ERB before approval can be granted. However, this latter review may be expedited. The number and magnitude of changes required, and therefore the time to final approval, will depend on the researchers' experience with the ethics review process, and on the ERB's experience with ESE research. To help researchers proceed more efficiently through the review process, below we discuss the types of documents usually submitted when seeking ethics approval and relate their contents to the foregoing material.

\section{Documents NeEded for ReVIEW}

In the course of preparing documents for a review, it is often helpful to have a set of example documents as a guide, as we provide here. However, it is important to remember that the specific set of documents required will vary from one ERB to another. Consequently, the most important part of preparing for a review is to consult the local ERB, or other department members who have been through the ERB process. We have found that the requirements and filing procedures are often available on the web.

As we cannot specify what individual institutions will require, this section will present generic examples of the type of documents usually required. Our web search showed that most institutions require that a proposal contain a cover letter, a project description, a consent form, and a scientific review (see also Sieber, 1992).

Each of the required documents is detailed below. Where appropriate, the elements of the document are related to the four ethical principles described earlier.

\subsection{Cover Letter}

The cover letter introduces the project to the ERB. It usually includes the principal investigators' names and contact information. It should be clear who will carry out the research and who will be responsible for its supervision and conduct. It is usually sufficient to provide information about the principal investigators only; the 
rest of the team need not be profiled. Also included in the cover letter is a note indicating whether the proposal relates to a new project, a changed project, or an annual review of an on-going project. If the project is a changed project or an annual review, the cover letter should also include the project ID, which is usually assigned at the time of initial approval.

The cover letter can include information about the qualifications of the researcher. This is especially useful for a first proposal submitted to the ERB. Including a curriculum vita as an appendix can serve the same purpose. Finally, the cover letter should include any additional information that the researchers believe will help the reviewers assess the proposal, such as experience with the same subject population, eagerness of the industrial site in maintaining subjects' rights, etc.

\subsection{Project Description}

The project description usually has several specific subheadings. The ERB will often ask researchers to respond to a set of standard questions referring to specific aspects of the research, such as whether deception will be used, or whether subjects will be drawn from a vulnerable population. Depending on the answers, researchers may have to provide additional explanations. The answers will also often determine whether the project is deemed of minimal risk, and so can undergo expedited review (refer to Sect. 3.2).

Figure 1 shows an example of a project description that describes some observational research we conducted at an industrial site. Because the study used employees as subjects (a vulnerable population), it was not deemed minimal risk, and was therefore reviewed by the full board. The ERB was particularly interested in recruitment and confidentiality issues.

\subsubsection{Project Overview}

The primary purpose of the project overview is to satisfy the ERB that the research being embarked upon addresses an important question. It usually begins with a short description of the project and its goals, including a short literature review. The project overview also usually includes a description of the study's design, including the specific procedures, tests, interviews and interview schedules, and samples of any questionnaires that will be used. Not everyone on the ERB will have expertise in software engineering, so the overview and procedures should be written for a layperson.

In general, the project overview allows the ERB to determine the project's scientific importance (although not validity), which in turn helps the ERB estimate scientific value and beneficence. If an ERB finds no scientific value to a project, it is conceivable that the proposal will be rejected. Consequently it is important that researchers fully motivate their research. Note that our example project overview was kept short to save space.

\subsubsection{Subjects}

The subjects section should contain a description of the subject population. If more than one type of subject is involved (e.g., chemistry students vs. computer science students), all types should be adequately described. In this section, researchers should include any information that helps the ERB understand why this particular subject group is being sought, e.g. computer science students are familiar with a particular language that relates to the study hypothesis. 


\title{
STUDIES OF SOFTWARE DEVELOPER WORK PRACTICES
}

\author{
PROJECT DEscription
}

\section{Project OVERVIEW}

In the past, software engineering tools have been designed based on the intuitions of designers and not the real needs of software engineers. The goal of this research is therefore to improve software engineering tools by gathering tool requirements from the software engineering community. Following, Lethbridge and Singer (1998), we will be studying the work practices of software engineers as they go about their daily work. Software engineers will be observed for one hour on one day. Portable computers and paper and pencil will be used to collect data. Additionally subjects will be asked to think out-loud while they perform their tasks. This think out-loud data will be tape-recorded. All subjects will be informed of their rights as subjects before participating. We will be under a non-disclosure agreement with the company pertaining to the results of the study.

\section{SUBJECTS}

Ten software engineers involved in the development of a large scale software engineering project will be selected as subjects for this experiment.

\section{CONFIDENTIALITY AND DATA STORAGE}

Because the data involves audiotapes where subjects may identify themselves or colleagues, the data cannot be cleared of identifying features. To ensure security, all tapes, transcripts of tapes, and computer logs will be stored in a locked filing cabinet in a locked office at the university. The only people who will have access to the data are the principal investigators and graduate students working with the team. All graduate students will be required to sign an agreement to not disclose information to anyone outside of the research team. When publishing results, all identifying information will be stripped from the data before it is published. If it is possible for identification to occur, subjects will be shown the paper and asked to give informed consent to the data usage before the paper is published.

\section{RECRUitMent PRocedures}

Senior company management have identified the groups for us to contact. Recruitment will occur via email to each group member. If a group member replies, a researcher will contact the group member by phone to give more details of the research. If the group member is still interested, an observation date will be set, at which time the group member will be given the subject information sheet and the consent form. If the member agrees, the observation will commence immediately. One week from the initial message, a reminder message will be sent to all group members who did not respond to the initial message. Regarding data collection, the researchers will ensure the confidentiality of the research subjects in two ways. First, the managers will not be told who participated in the research. Second, the researchers will randomly sample from those subjects who have indicated a willingness to participate. In this way, the managers will not know whether subjects were simply not chosen to participate or whether they chose not to participate.

Subjects will not be compensated for participating in this research.

\section{BENEFITS, HARMS AND INCONVENIENCES}

There is no direct benefit to the subject for participating in this research. There is a benefit to the software engineering community in the form of improved requirements for tool design to support maintainers. There are no harms to participating in this research. Subjects may feel slightly intimidated at the beginning of observation sessions, but in previous research this has abated quickly. 
Fig. 1 An example of a project description form. See Sect. 4.2 for greater detail

The subjects section should also subtly convey the subject group's familiarity with the types of risks that will arise from participation in the experiment. The following example illustrates how ethical concerns can change as a function, not of methods, but of subject group. Consider an experiment in which subjects experience a simulated airplane crash. If the subjects are test pilots, we can be sure that they will have the knowledge and experience required to make a reasonable decision about participation. If the subjects are undergraduates, we have to be sure that the risks of participation are clearly disclosed. If the subjects are senior citizens, the risks of injury may be too great for the study to go forward. A description of the subject groups' familiarity with the risks will therefore help the ERB in its evaluation.

Similarly, the subjects' context in regard to coercion or undue influence could be described. One concern in research is that people could agree to participate simply because they perceive the researcher as a trusted authority who should be obeyed (Kelman, 1972). This risk is even greater in medical research when a doctor adopts the role of experimenter (Beecher, 1966b; Canadian Institutes of Health Research et al., 2005; National Health and Medical Research Council et al., 2007). An ERB once raised a similar objection to the author (Singer) recruiting SEs in person. The ERB was concerned that the SEs would be intimidated by Singer's (as the board perceived it) higher social status, and so would feel pressure to volunteer. The ERB felt the SEs would be less intimated (and therefore less pressured) if the request took place through e-mail. While this concern is unwarranted when it comes to North American SEs, it is a legitimate concern in general (Kelman, 1972). Cultural differences could also have an impact, such that social status differences could affect the recruitment of SEs for studies taking place outside North America. Moreover, other social variables, such as age or gender, could also have an impact. Consequently, a short explanation of the role played by social differences between SEs and researchers in recruitment should help the ERB with its assessment of the proposal.

Of course, the real problem for voluntariness in ESE is not social status but the subject's position in the organizational hierarchy, which can lead to undue influence, if not coercion (Kelman, 1972) (refer to our section on informed consent). The subject's position in the organization should be described here. Any mitigations of the undue influence should be described in the relevant project description sections (e.g. Recruitment Procedures).

Finally, ERBs are often concerned that neither the burden nor benefits of research are disproportionally felt by a particular social group (Canadian Institutes of Health Research et al., 2005; National Health and Medical Research Council et al., 2007; Penslar, 1993). In ESE, this concern is most likely to manifest itself in the scrutiny of any inclusion or exclusion criteria proposed by the researcher. For example, researchers may want to exclude experienced SEs from their study. Any such criteria will have to be justified.

\subsubsection{Confidentiality and Data Storage}

In this section, measures to secure the data should be described. The ERB will want to ensure that data are protected from theft, interception, unauthorized reading and copying. To maintain security, data is often stored in a locked facility that can only be accessed by members of the research team. Some additional means of protecting data are described above in the section on confidentiality.

Since studies with vulnerable subject populations (employees and students) are common in ESE, this section might also include a description of the measures taken to protect the subjects' identities.

\subsubsection{Recruitment Procedures}


Since our example subjects are employees in an industrial setting (with the prior consent of their managers), there is a possibility of coercion in the recruitment process. Thus, we included a separate section in our project proposal detailing how we would recruit subjects while minimizing the possibility of coercion. An example e-mail message for potential subjects is included so an ERB can ensure that the language is neutral and does not in any way coerce the employees to participate in the study (e.g. by mentioning that their manager thought the information gained would be highly valuable to the company).

There are three important aspects to our recruitment procedures. First, recruitment is conducted via e-mail rather than in person. Second, the recruitment e-mail message emphasizes that participation is voluntary and that no harm can come from a refusal to participate. Finally, the e-mail message is sent to a larger pool of potential volunteers than is necessary given the experimental design to help ensure the anonymity of subjects.

ERBs will want to know whether subjects are being compensated for participation. The ERB wants to ensure that compensation is not so great that it will induce subjects to take risks that they would not normally take. This is easy to understand in the context of a medical study. For example, giving homeless subjects an excessive monetary reward for participating in risky medical research would be deemed highly unethical, because it would be seen as a form of implicit coercion. In software engineering studies, it is unclear what an appropriate compensatory scheme would be. Researchers intending to provide compensation to subjects should provide the ERB with adequate information to understand the compensatory scheme (e.g., software engineers will be paid in line with their salary on an hourly basis).

The ERB will also sometimes require a delay between the time the subject is given information about the study and the time at which the subject actually consents to participate. This is important in medical studies where the ERB needs to make sure that the subjects fully consider the risks of participation, but it can also be required in lower risk studies.

The ERB will also want to ensure that appropriate recruitment measures have been taken to ensure the study's validity.

It is advisable to provide more, rather than less, detail about how subjects will be approached and recruited. Recruitment is at the heart of some very delicate ethical matters (such as confidentiality and voluntariness of informed consent), and therefore the ERB will be quite serious in ensuring that recruitment is conducted appropriately.

\subsubsection{Benefits, Harms, and Inconveniences}

The degree of acceptable research risk depends on several factors, as mentioned in our section on beneficence. Consequently, the judgment of what constitutes an acceptable risk can vary dramatically depending on the context of the research and the risks to which subjects from a particular group are typically exposed. For example, because of their situation, terminal cancer patients can incur more risk as part of research into a treatment for their cancer than would be acceptable, say, for healthy children. Consequently, when writing a proposal for ethics review, it is advisable to clearly present the risks and benefits subjects will incur through the proposed research. However, we do not recommend that researchers try to anticipate ERB objections by listing a series of potential risks that will not arise out of the proposed research. This exposes researchers to being required to provide additional information on each of the measures put in place to eliminate those risks. It is important to recall that beneficence involves considering the relationship between risks and benefits for the subjects and society. Consequently, it is important to also clearly specify any benefit that may accrue from the research. 


\subsubsection{Deception}

It would be unusual for an ESE study to employ outright deception. The section on deception will therefore typically state that no deception will be employed. It is important to remember that partial disclosure is not deception. Partial disclosure and deception are discussed earlier in the section on informed consent.

\subsection{INFORMED CONSENT}

In order to give fully informed consent, subjects must be given all the information needed to decide whether to participate in the research. In our proposal, we used two forms. The first is a subject information sheet providing subjects with an understanding of the research process and their potential involvement (Fig. 2). The second form is the actual consent form (Fig 3).

Generally, researchers will bring two copies of the informed consent form to the subject. The subject will keep one copy for his reference, and return a signed copy for the researchers' records.

In participant/observation or ethnographic studies, where the researcher assumes the role of an SE, it is impractical (if not impossible) to obtain written consent from everyone the researcher encounters. Regulations offer some flexibility in the informed consent process (American Anthropological Association, 2004; Canadian Institutes of Health Research et al., 2005; Penslar, 1993) but ERBs have been reluctant to avail themselves of this flexibility (American Anthropological Association, 2004; Fleuhr-Lobban, 1994). Our suggestion to researchers is to attempt to ensure that every subject who is at risk of harm provide written consent, and to emphasize this to the IRB.

\subsubsection{Subject Information Sheet}

Though some ERBs do not require it, we have found it helpful to group all the important information on one sheet (Fig. 2). The subject information sheet contains the information necessary for the subjects to decide whether to participate in the research. It should also inform subjects of some of their basic rights, such as the right to withdraw without penalty.

It begins with a brief statement of the background, purpose, and goals of the research. The sheet should be comprehensible to the potential subjects. Jargon should be avoided, but if technical terms will help explain the research, and the potential subjects will understand the terms, then it is appropriate to use them.

The subject information sheet contains other pertinent information including how the subjects were chosen; whether their employer has given them permission to participate; the location of the research; and finally what is expected of them and how long the their tasks will take. In observational studies, there is no experiment per se, so subjects are generally told to engage in their normal behaviour but to be aware that they might be observed.

The next section informs the subjects that their participation is voluntary and that they may withdraw consent at any time without any consequences. All informed consent forms will require such a statement to support the voluntariness of the informed consent. The next several statements address confidentiality. Generally these statements describe the confidentiality provisions as well as the limits on confidentiality, if any. In our example, we assure the subjects that their employer will not know whether they participated and will not have the opportunity to look at an individual's data. The subjects are also told that another informed consent will be sought if it turns out that the reports could lead to the identification of individual subjects. The subject information sheet assures subjects that they can look at their data at any time. In some cases, subjects are informed that their data will be destroyed at their asking. 


\section{STUDIES OF SOFTWARE DEVELOPER WORK PRACTICES}

\section{SUBJECT INFORMATION SHEET}

Traditionally, tools for software maintenance engineers are designed without knowing much about the specific circumstances under which software maintenance engineers work. Our research aims to correct this oversight by studying software maintenance engineers as they go about their daily work. We want to know not only where you spend your time, but also how you go about solving problems, what sources of information you consult, how you interact with the software and hardware, and what you find the most enjoyable and the most difficult aspects of your work.

Participants for this project will be selected via their place of employment. As part of the CSER initiative, certain corporations have agreed to allow us access to their employees. Your employer has specified your group as a possible source of participants in our research. The research will occur in your place of employment. If you consent to participate in our research, we will observe you as you go about your work in one 1 hour sessions. You simply do what you would normally do, and we use a computer or paper and pencil to record your actions. Occasionally, we ask for clarification on a certain procedure, but in general try to be silent observers.

Participation in this research project is voluntary. Participants can withdraw their consent to participate and discontinue participation at any time without any consequences. Your employer will not know whether or not you have participated, or whether or not you have withdrawn participation. All collected data is strictly confidential, it will not be made available to anyone (including your employer) except as aggregate data. In the case that you may be identified in any reports, the researchers will ensure that you consent to the publication. Collected data will only be used by members of this research project as analysis vehicles for understanding the work practices of software maintenance engineers. The data will not be used for any other purpose. All participants can review their own data at any time.

All participants have the right to obtain any publicly available documents that are published about this research. All data collected is stored in a locked office at the National Research Council or the University of Ottawa.

Fig. 2 An example of a Subject Information Sheet, as described in Section 4.3.1

The subject information sheet ends by telling subjects that they have the right to published reports of the research. Additionally, it tells subjects where the data will be stored.

Note that the subject information sheet is written from the perspective of the researcher providing explanations to the potential subject, whereas the informed consent form is written from the perspective of the subject. That is, the statements in the informed consent form begin with "I" and are not simply informational.

\subsubsection{Consent Form}

\subsubsection{Research Project Title}

The informed consent form (see Fig. 3) must always include the title of the research project as it appears in the documents submitted to the ethics board, so the subjects can correctly refer to the research should they wish to contact someone about their participation, e.g., to complain about their experience. 


\subsubsection{CONTACT INFORMATION}

The informed consent form should also always provide a research contact and an ethics contact. The research contact is the person the subjects would contact if they have any questions about the research, including obtaining results or papers, scheduling sessions, etc. The ethics contact is usually someone in the researcher's organization who acts as an ethics ombudsman. This is the person whom subjects should contact to voice any concerns about the way they were treated during the research project, such as feeling coerced into participating. It is the responsibility of the ethics contact's office to take complaints, investigate them, and decide upon actions where warranted.

\subsubsection{CONSENT AND COMPREHENSION}

In this section, the subjects are actually giving their consent to participate in the research project. This section also addresses the subjects' comprehension of the proposed research. The subjects are basically stating that they understand what is required of them, and that they understand that they will be participating in a research project.

\section{STUDIES OF SOFTWARE DEVELOPER WORK PRACTICES}

INFORMED CONSENT

I hereby give my consent to participate in the research proposal, Study of Software Maintenance Engineers. I have been given a copy of the Subject Information Sheet. I have read this sheet and understand what it says. I understand that this project involves research. I understand the procedures that will be used.

I understand that my consent can be withdrawn at any time without any consequences.

I understand that I can view the data pertaining to me. I understand that all collected data is strictly confidential and will not be seen by anyone except members of the research team, or as aggregate data. I understand that all data is kept in locked offices at the NRC or University of Ottawa.

I understand that this research will be used to better understand the work practices of software maintenance engineers and this in turn will lead to better tool design. I understand that beyond this, there is no personal benefit to me for participating in this research. I also understand that there is no harm to me for participating in this research. There may be minor inconveniences as the researchers set up their equipment. I understand that I will not receive any payment for my participation in this research.

I understand that I may request additional information about this research at any time, but as of now, all of my questions have been answered.

\section{Ethics Contact}

Dr. Ellen Good, Ethics Ombudsman

Some University

(888) 555-1212

ellen.good@someuni.edu

\section{Research Contact}

Dr. Sam Jones

Some University

(888) 555-1212

sam.jones@someuni.edu

Name (Printed)

Signature

Date

Fig. 3 An example of an Informed Consent Form 


\subsubsection{WITHDRAWAL}

This section states that the subjects' signatures attest to their understanding that they can withdraw from the research project without penalty. All informed consent forms will require such a statement. This feature reinforces the voluntariness of the consent.

\subsubsection{CONFIDENTIALITY}

Here the provisions of confidentiality regarding the research project and the data are reiterated.

\subsubsection{RISKS AND BENEFITS}

Here the subjects are asked to consent to the risks and benefits incurred from participating as a subject. Note that the form states that the subjects do not give up any legal rights by signing it.

\subsubsection{CLARIFICATION}

This statement regards the subjects' understanding that they can request additional information at any time. It also ensures that all the subjects' questions have been answered. Remember that in order to give fully informed consent, the subjects must completely understand their role in the research project. This statement just ensures that they have been given the opportunity to do so.

\subsubsection{SIGNATURE}

Finally, in all informed consent forms, the subjects are required to sign and date the form appropriately. The experimenter is often also required to sign. Subjects are then given a copy of the subject information sheet and the informed consent form. In some cases, verbal assent is sufficient. For instance, with surveys or questionnaires, the assent implied by filling out and returning the document may be considered sufficient evidence of consent by the ERB.

\section{CONCLUSION}

In this chapter we have presented four ethical principles that form the core of several research ethics guidelines and codes: informed consent, beneficence, confidentiality, and scientific value. How can one ensure that ethics plays a role in a research project? First, and foremost, researchers must educate themselves about ethics, just as they would about methodology or data analysis. This includes educating graduate and undergraduate students about the primary tenets behind ethical research. Ideally, this education should include practical as well as classroom experience. Researchers can also share their experiences with others so that the community as a whole develops its competency in this area.

Researchers also need to plan for ethics in their research, as one cannot always quickly solve problems as they occur. For instance, in conducting a classroom study, researchers need to have a plan for those students who do not wish to participate. Building likely scenarios can help researchers to understand specific issues and have solutions in place to address them.

Finally, researchers need to consult others who can help them to plan and implement ethical research. For instance, ERBs have a great deal of expertise on ethics and research. Researchers can use this important resource early in the planning stages to address potential problems. This has the added advantage of educating local ERBs on topics of importance to ESE researchers. 
Ethical research does not happen by chance. Individual researchers must be committed to making their research ethical. By addressing some of the issues surrounding ethics in ESE research, we hope to have given ESE researchers the understanding they need to reason ethically about their own work.

\section{ACKNOWLEDGEMENTS}

We would like to thank Paula Desjardins for her assistance in conducting a survey of the types of documents submitted to ERBs.

\section{REFERENCES}

ACM Executive Council. (1993). ACM code of ethics and professional conduct. Communications of the ACM, 36(2), 99-105. http://www.acm.org/constitution/code.html

American Anthropological Association. (2004). Statement on Ethnography and Institutional Review Boards. http://www.aaanet.org/stmts/index.htm

American Psychological Association. (2002). Ethical Principles of Psychologists and Code of Conduct. http://www.apa.org/ethics/code2002.html Anderson, R. E., Johnson, D. G., Gotterbarn, D., \& Perrolle, J. (1993). Using the new

ACM code of ethics in decision making. Communications of the ACM, 36(2), 98-107.

Australian Research Council (ARC). (2007). Research Ethics. www.arc.gov.au/about_arc/ research_ethics.htm

Becker-Kornstaedt, U. (2001). Descriptive software process modeling - how to deal with sensitive process information. Empirical Software Engineering, 6(4), 353-367.

Beecher, H. K. (1966a). Ethics and clinical research. New England Journal of Medicine, 274(24), 1354-1360.

Beecher, H. K. (1966b). Consent in clinical experimentation: myth and reality. Journal of the American Medical Association, 195(1), 124-125.

Canadian Association of University Teachers (CAUT). (1997, October). CAUT responds to tricouncil code. CAUT Bulletin. www.caut.ca/en/bulletin/issues/1997_oct/tricouncil.htm

Canadian Institutes of Health Research, Natural Sciences and Engineering Research Council, \& Social Sciences and Humanities Research Council. (2005). Tri-Council Policy Statement: Ethical Conduct for Research Involving Humans. Public Works and Government Services Canada. www.pre.ethics.gc.ca

Committee on Science, Engineering and Public Policy of the National Academy of Sciences, National Academy of Engineering, and Institute of Medicine. (1992). Responsible Science: Ensuring the Integrity of the Research Process (1). Washington DC: National Academy Press.

Committee on Science, Engineering and Public Policy of the National Academy of Sciences, National Academy of Engineering, and Institute of Medicine. (1993). Responsible Science: Ensuring the Integrity of the Research Process (2). Washington DC: National Academy Press. 
Committee on Science, Engineering and Public Policy of the National Academy of Sciences, National Academy of Engineering, and Institute of Medicine. (1995). On Being a Scientist: Responsible Conduct in Research (2nd edn). Washington DC: National Academy Press.

Economic and Social Research Council (ESRC). (undated). Research Ethics Framework. Swindon, UK: ESRC. http://www.esrcsocietytoday.ac.uk/ESRCInfoCentre/Images/ESRC_Re_Ethics_Frame_tcm6-11291.pdf

El-Emam, K. (2001). Ethics and open source. Empirical Software Engineering, 6(4), 291-292.

Engineering and Physical Sciences Research Council (EPSRC). (2007). Funding Guide. Swindon, UK: EPSRC.

Faden, R. R. \& Beauchamp, T. L. (1986). A History and Theory of Informed Consent. New York: Oxford University Press.

Fleuhr-Lobban, C. (1994). Informed consent in anthropological research: we are not exempt. Human Organization, 53(1), 1-10.

Fowler, F. J. Jr. (1993). Survey Research Methods (1) (2nd edn). Thousand Oaks, CA: Sage.

Frankel, M. S. (1989). Professional codes: why, how, and with what impact? Journal of Business Ethics, 8(2), 109115.

Freedman, B. (1987). Scientific value and validity as scientific requirements for research: a proposed explication. IRB: Ethics and Human Research, 9(6), 7-10.

Gotterbarn, D., Miller, K., \& Rogerson, S. (1999). Software engineering code of ethics is approved. Communications of the ACM, 42(10), 102-108.

Harrison, W. (1998). An issue of ethics: responsibilities and obligations of empirical software engineering researchers. Empirical Software Engineering, 3, 7-9.

Heath, E. (1998). The noninstitutional review board: what distinguishes us from them? IRB, 20(5), 8-11.

Jeffrey, D. R. \& Votta, L. G. (1999). Guest editor's special section introduction. IEEE Transactions on Software Engineering, 25(4), 435-437.

Kelman, H. C. (1972). The rights of the subjects in social research: an analysis in terms of relative power and legitimacy. American Psychologist, 27, 989-1016.

Lane, B. (2006, August 16). Ethics draft provokes anger. The Australian. http://www.theaustralian.news.com.au/

Lethbridge, T. C. (2001). Mixing software engineering research and development - what needs ethical review and what does not? Empirical Software Engineering, 6(4), 319-321.

McNeill, P. (1993). The Ethics and Politics of Human Experimentation. New York: Cambridge University Press.

Mirvis, P. H. \& Seashore, S. E. (1982). Creating ethical relationships in organizational research. In J. Sieber (Ed.), The Ethics of Social Research, New York: Springer-Verlag, (pp. 79-104). 
National Health and Medical Research Council, Australian Research Council, \& Australian Vice-Chancellors' Committee. (2007). National Statement on Ethical Conduct in Human Research. Australian Government.

Organisation for Economic Development and Co-operation (OECD). (1980). OECD Guidelines on the Protection of Privacy and Transborder Flows of Personal Data. OECD.

Patrick, A. S. (2006). Privacy practices for $\mathrm{HCl}$ research. HOT Topics!, 5(2). http://www.carleton. ca/hotlab/hottopics/Articles/February2006-PrivacyPract.html

Penslar, R. L. (1993). Protecting Human Research Subjects: Institutional Review Board Guidebook. Washington DC: National Institutes of Health, U.S. Government Printing Office. www.hhs.gov/ohrp/irb/irb_guidebook.htm

Public Welfare, Protection of Human Subjects, Code of Federal Regulations, Title 45, Pt. 46 (45CFR§46), (2005), http://www.hhs.gov/ohrp/humansubjects/guidance/45cfr46.htm

Schrier, J. (1992). Reducing stress associated with participating in a usability study. In Proceedings of Human Factors' Society 36th Annual Meeting, Santa Monica, CA.

Sieber, J. E. (1992). Planning Ethically Responsible Research: A Guide for Students and Internal Review Boards (31). Thousand Oaks, CA: Sage.

Sieber, J. E. (2001a). Not your ordinary research. Empirical Software Engineering, 6(4), 323-327.

Sieber, J. E. (2001b). Protecting research subjects, employees and researchers: implications for software engineering. Empirical Software Engineering, 6(4), 329-341.

Singer, J., Sim, S. E., \& Lethbridge, T. C. (2008). Software engineering data collection for field studies. In F. Shull et al. (Eds.) Guide to Advanced Empirical Software Engineering, Springer.

Singer, J. \& Vinson, N. G. (2002). Ethical issues in empirical studies of software engineering. IEEE Transactions on Software Engineering, 28(12), 1171-1180.

Singer, J. \& Vinson, N. (2001). Why and how research ethics matters to you. Yes, you!. Empirical Software Engineering, 6(4), 287-290.

Smith, S. \& Richardson, D. (1983). Amelioration of deception and harm in psychological research: the important role of debriefing. Journal of Personality and Social Psychology, 44(5), 1075-1082.

University of Toronto Social Sciences and Humanities Research Ethics Board (SSH REB). (2005). Guidelines for Ethical Conduct in Participant Observation. http://www.research.utoronto.ca/ ethics/eh_policy.html

Vinson, N. \& Singer, J. (2001). Getting to the source of ethical issues. Empirical Software Engineering, 6(4), 293297.

Vinson, N. G. \& Singer, J. (2004). Consent issues raised by observational research in organisations. NCEHR Communiqué, 12(2), 35-36.

Worchel, S. \& Cooper, J. (1979). Understanding Social Psychology, Revised Edition. Homewood, IL: The Dorsey Press. 
Vinson \& Singer

Wright, D. R. (2006). Research ethics and computer science: an unconsummated marriage. In Proceedings of SIGDOC '06, Myrtle Beach, SC, USA. 